\title{
In Situ Generation of Ammonia: an Efficient Catalyst for the Synthesis of Phenol-Aniline-Formaldehyde Resol Resins
}

Apparav Walea, Khudbudin Mulanib, Kamini Dondeb, Surendra Ponrathnama, Nayaku Chavana,*

a Chemical Engineering and Process Development Division, National Chemical Laboratory

Dr. Homi Bhabha Road, Pashan, Pune - 411008, India

${ }^{b}$ Department of Chemistry, Ramnarain Ruia College, Matunga, Mumbai

\section{ART I CLE I N F O}

Received: 24 May 2019

Revised: 14 July 2019

Accepted: 20 August 2019

Available online: 21 August 2019

\section{K E Y W O R D S}

Phenol-aniline-formaldehyde resins In-Situ

Ammonia

Resol

Thermal Properties

\section{A B S T R A C T}

A novel method developed for the synthesis of resol based phenol-anilineformaldehyde (PAF) resins by in situ generation of ammonia using magnesium hydroxide and ammonium chloride as reagents in the presence of phenol, aniline and formaldehyde. The synthesized PAF resol resins were characterized by IR, NMR spectroscopic methods, thermal stability by thermogravimetric analysis (TGA) and thermal properties by differential scanning colorimerty (DSC). Free phenol and free aniline of PAF resins were determined using gas chromatography and also these resins characterized for elemental analysis, inherent viscosity, molecular weight and gel time. DSC results illustrated that the glass transition temperatures of PAF resins exhibited in the range of $72-110^{\circ} \mathrm{C}$, whereas TGA results depicted that the thermal stability of the PAF resins revealed in the range of $516-548{ }^{\circ} \mathrm{C}$. In situ generation of ammonia showed higher thermal stability and lower content of free phenol and free aniline in PAF resin.

G R A P H I C A L A B S T R A C T

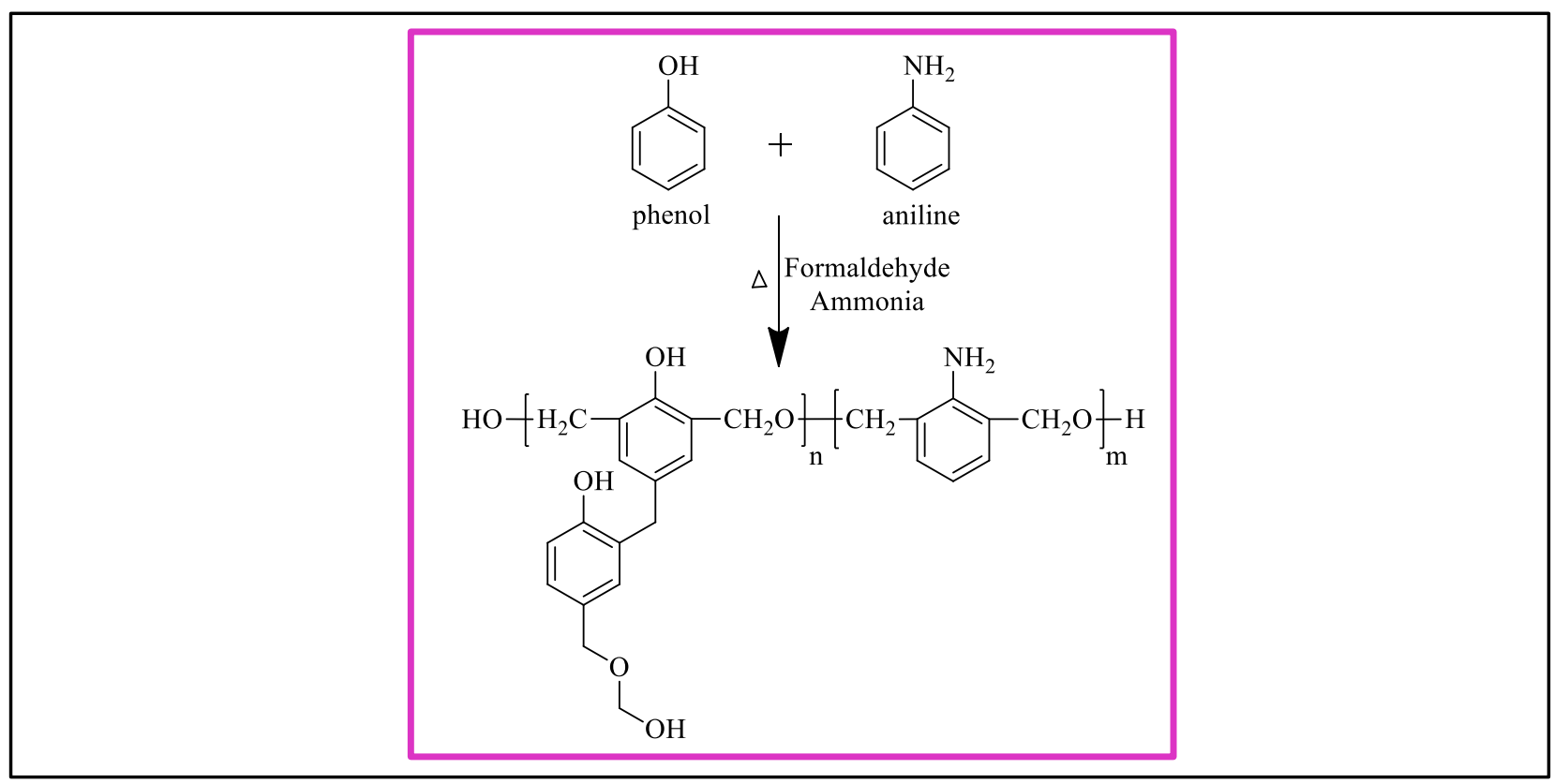

* Corresponding author's E-mail address: nn.chavan@ncl.res.in 


\section{Introduction}

Phenolic resins are considered to be one of the big families of oligomers and polymers. These resins comprised variety of structures based on the reaction products of phenols with formaldehyde. Phenolic resins were originally developed in the early twentieth century. The nature and potential of phenolic resins have been explored thoroughly, which has produced an extensive body of technical literature. Phenolic resins are employed in a wide range of applications, from commodity construction materials to high technology applications in microelectronic and aerospace. Phenolic resins provide numerous challenges in synthesis, characterization, production, product development, and quality control.

Phenolic resins are amongst the most popular condensation polymers. In early days, these resins were used in molded parts, insulating varnishes, laminated sheets, and industrial coatings. But now a day's these resins are also used in wood bonding, fiber bonding, and as plywood adhesives. They are mostly used in a wide range of applications such as construction, automotive, foundry resins, composite wood material, electrical and appliance industries [1]. Due to the high temperature resistance, infusibility and flame retardant properties, phenolic resins are employed in the wide range of applications particularly in electronics and aerospace. The most important application of phenolic resin is in the manufacturing of high performance composites in construction of aerospace components [2].

Since phenolic resins have a wide range of applications, researchers focus on how to affect preparation conditions on resin properties. Many synthesis parameters such as phenol/formaldehyde ratio, type and amount of catalyst, $\mathrm{pH}$ and temperature influence the molecular structure and properties of resulted resins [3-4]. Phenolic resins usually exist in two types depending on $\mathrm{pH}$, their structure and curing processes namely novolac and resole. The novolac resins prepared from acid catalyst and having phenol: formaldehyde ratio is around 1:0.8, and these resins are almost unable to crosslink or cure without curing agent $[5,6]$. However, resole resins produced in which phenol: formaldehyde ratio ranges from 1:1 to 1:3 under alkaline condition [6]. Over the last three decades, many authors have reported influence of phenol to formaldehyde molar ratio and catalyst type on resulting phenolic resol resins [7-10].

Certainly, phenol-aniline-formaldehyde (PAF) resins exhibit better heat resistance and dielectric insulation properties for electric insulation applications. Due to the important applications, phenolic resins have been widely used for the production of molded products. Nicolas et al., patented the method for the preparation of resinous material by reacting phenol with a primary amine e.g. aniline, toluidine and xylidine [11]. The well-known procedure for the curing of phenolic resins is strong acid treatment. For these purpose hydrochloric acid, phosphoric acid, sulphuric acid, trichloroacetic acid and $p$-toluene sulphonic acid are used traditionally. These acids are used either alone or mixture of two or more. In the special application, the phenolic resins are cured in presence of reinforcing agents such as cellulose, glass fibers, non-woven fibers made of high molecular weight polyester, polyvinyl chloride etc. In order to avoid losing of phenolic resins during hardening, reduction in concentration of acid hardener solution is preferable. Bender and co-worker patented a process of hardening phenol-formaldehyde resins in presence of aniline [12].

Studentsov and Artemenko reported the hardening of phenol-aniline-formaldehyde resins in presence and absence of fibers. In this article, kinetics and mechanism of hardening in phenol-aniline-formaldehyde 
resins without fillers and mixed with different fibers were studied [13]. The water insoluble thermosetting resin prepared from the reaction of phenol, formaldehyde and aniline in presence of reducing sugar as invented by Ingrassia and co-workers [14].

Furthermore, Dalibor et al., discovered the process of phenol-aniline-formaldehyde condensation product plasticized with epoxidized soya oil. The aim of this invention was to study the effect of epoxidized unsaturated fatty acid radical containing natural glycerides such as soya oil, sunflower oil and linseed oil on PAF condensation product [15]. Currently, various types of catalysts are used for condensation of phenol and formaldehyde, alkaline earth metal hydroxides are one of them. The calcium hydroxide is also used as catalyst for condensation reaction between phenol and formaldehyde to impart better moisture stability. The main advantage of this catalyst over other alkali metal hydroxides is easily precipitated from the condensation product by the addition of dilute sulphuric acid, carbon dioxide, ammonium sulphate and ammonium phosphate to form water soluble calcium salts. The method for the preparation of moisture stable phenolic resins comprises condensation of phenol and formaldehyde in presence of calcium hydroxide as catalyst has been patented by Jellinek and co-workers [16].

Generally, in the synthesis of phenolformaldehyde resol resin, ammonia is used as basic catalyst. When the ammonia is used, it helps to separate reaction mixture containing aqueous phase and organic phase after the completion of reaction, because the initial reaction product is considered to be less hydrophilic [17].

It is well known that ammonia is a gas and its melting point is $-57.5^{\circ} \mathrm{C}$ whereas boiling point is $37.7^{\circ} \mathrm{C}$. Thus, ammonia solution is prepared with water and used as catalyst and its maximum concentration exceed up to $30 \%$.
Due to the low boiling point the concentration of ammonia decreases as the reaction time increases, particularly at high temperature reaction. Hence, it may affect the conversion, yield of reaction and physical properties of the final product. Therefore, we designed a new method for the generation of ammonia, i.e. insitu. Because of this method ammonia will remain in reaction till end of the reaction time and will not affect the concentration of catalyst.

From the curing point of view, paramethylol groups react more easily with other functional groups at higher reaction rates than ortho-methylol groups. Thus, proportion of para-methylol groups to ortho-methylol groups should be higher to cure more rapidly phenol-formaldehyde resins [18]. The cure time significantly influences the productivity and cost of the resin-based materials. Fraser et al. [19] and Huang et al. [20] reported that bivalent metal ions such as $\mathrm{Mg}^{2+}$ promotes the polymerization of ortho-methylol groups to more para-methylol groups in phenolformaldehyde resin. Thus, magnesium based catalyst is preferred for the synthesis of PAF resol resin.

In the present work, the resol based phenolic resins were synthesized by in situ generation of ammonia using different inorganic basic catalysts and reaction conditions. The synthesized phenol-anilineformaldehyde (PAF) resins were characterized by IR, NMR, TGA and DSC. The molecular weight, viscosity, gel point and MALDI-TOFF analysis were also reported.

\section{Experimental}

\section{Materials}

Aniline (99.5\%), ammonia (25\%) and formaldehyde $(37 \%)$ were procured from Merck India. Phenol (99\%) was purchased from S.D. Fine Chem Ltd. India. Magnesium hydroxide (95\%), calcium hydroxide (95\%) and ammonium chloride (99\%) were received 
from Loba Chemie Pvt. Ltd. India. All chemicals were used as received without any purification.

Gas liquid chromatography with flame ionization detector (GLC-FID)

Gas chromatograph Model GC-2010 (Shimadzu Corporation, Kyoto, Japan) equipped with an Auto sampler (HTA, Germany) and FID was used for the analysis. Hydrogen gas was purchased from Inox, Mumbai. Zero air and "A" grade nitrogen for FID flame ignition was supplied from Air Generator (Domnick Hunter, USA make). The data acquisition and processing was carried out on computer using Shimadzu's GC Solution Software. The weighing of standards and phenolic resin samples were carried out on digital balance (Mettler Toledo AG 245).

\section{IR spectroscopy}

FTIR spectroscopy study was performed on FTIR (Perkin-Elmer) instrument using potassium bromide pellet. Solid samples were milled with potassium bromide ( $\mathrm{KBr}$ ) to form a very fine powder. This powder was then placed in to the die and compressed into the Qwik Handi-Press for 2 minutes to form a pellet. IR spectra were collected in the wave number range between 4000 and $450 \mathrm{~cm}^{-1}$ at resolution $8 \mathrm{~cm}^{-1}$.

\section{NMR spectroscopy}

${ }^{1} \mathrm{H}$ NMR and ${ }^{13} \mathrm{C}$ NMR spectra were recorded on a $200 \mathrm{MHz}$ Brüker spectrometer using dimethyl sulfoxide (DMSO- $\mathrm{d}_{6}$ ) as solvent. The $5 \mathrm{mg}$ resin was dissolved in 0.5 $\mathrm{mL}$ dimethyl sulfoxide (DMSO- $\mathrm{d}_{6}$ ) as solvent. The proton and carbon chemical shifts were recorded in ppm and calibrated on the TMS solvent as internal standard.

\section{Thermogravimetric analysis (TGA)}

The thermogravimetric analysis is an important thermal analysis which shows the thermal stability of the polymers as well materials. Also, the profile of decomposition process and char yield of the material associated with the thermal treatment can be obtained. Thermogravimetric analysis (TGA) and differential thermogravimetry (DTG) analysis of uncured resin were carried out in PerkinElmer-7 instruments analyser, using alumina pans (5-10 mg), under nitrogen atmosphere $(20 \mathrm{~mL} / \mathrm{min})$ at heating rate of 10 ${ }^{\circ} \mathrm{C} / \mathrm{min}$ to determine thermal stability and char yield. $\mathrm{T}_{\max }$ was determined from differential themogravimetry (DTG) curve.

\section{Differential scanning calorimetry (DSC)}

Differential scanning calorimetry (DSC) measurement is used to get a thermal profile of the investigated sample under the conditions of thermal dynamic or isothermal scanning. The results of the measurements produce the knowledge of the reaction behavior, the beginning, the end and at which point the reaction reach its maximum peak. It also gives the heat of reaction and the glass transition temperature when operated under dynamic scanning. Differential scanning calorimetry was carried out on TA instruments Q-100 and Mettler DSC-20 instruments at heating rate of $10{ }^{\circ} \mathrm{C} / \mathrm{min}$ in nitrogen atmosphere to determine melting endotherms and glass transition temperatures.

\section{Elemental analysis}

Elemental analysis was performed on Flash EA 1112 series, Thermo Fischer, Scientific.

\section{Viscosity}

Solution viscosity of PAF resins were determined using Ubbelohde viscometer at 25 ${ }^{\circ} \mathrm{C}$. The polymer was weighed $(100 \mathrm{mg}$ ) in 25 $\mathrm{ml}$ graduated stopper flask and dissolved in THF (10 mL) up to mark. The solution was 
added in capillary viscometer and viscometer was placed in a constant temperature water bath. Thermal equilibrium was obtained within the solution. The liquid was then brought above the upper graduation mark on the viscometer. The time for the solution to flow from the upper to lower graduation marks was recorded.

Matrix assisted laser desorption ionization time of flight mass spectroscopy (MALDI-TOF MS)

Matrix assisted laser desorption ionization/time of flight/mass spectroscopy (MALDI/TOF/MS) measurement was performed on a Voyager-DE STR Biosystem. The $\mathrm{N}_{2}$ laser wavelength was $337 \mathrm{~nm}$, and the accelerated voltage for time-of-flight (TOF) mass spectrometer was $20 \mathrm{kV}$. The sample was dissolved in THF, and the matrix solvent was sinapinic acid.

\section{Experimental procedure}

The monomer composition for PAF resins are presented in Table 1. These PAF resins were synthesized using following methods.

Method 1: Weighed accurately requisite amount of phenol and aniline in $100 \mathrm{~mL}$ single necked round bottom flask equipped with magnetic stirrer and water condenser. To the above mixture added requisite quantity of formaldehyde and magnesium hydroxide and was refluxed at $80^{\circ} \mathrm{C}$ for $4 \mathrm{~h}$. The reaction mixture was cooled to room temperature and water was removed by vacuum distillation at $50^{\circ} \mathrm{C}$. Viscous resinous material obtained was dried under reduced pressure at $80{ }^{\circ} \mathrm{C}$ for $6 \mathrm{~h}$.

Method 2: Ammonia was generated in situ using magnesium hydroxide and ammonium chloride as reagents and sample was coded as LSPR-5. The condensation reaction is presented below.

$\mathrm{Mg}(\mathrm{OH})_{2}+2 \mathrm{NH}_{4} \mathrm{Cl} \rightarrow 2 \mathrm{NH}_{3}+\mathrm{MgCl}_{2}+2 \mathrm{H}_{2} \mathrm{O}$

The quantity of monomers and catalysts used in the synthesis of PAF resin is presented in the Table 1.

Table 1. Monomer composition for aniline-phenol-formaldehyde resins

\begin{tabular}{|c|c|c|c|c|c|c|}
\hline $\begin{array}{l}\text { Resin } \\
\text { Code }\end{array}$ & $\begin{array}{l}\text { Phenol } \\
\qquad(\mathrm{g}) \\
(\mathrm{mol})\end{array}$ & $\begin{array}{l}\text { Aniline } \\
\text { (g) } \\
\text { (mol) }\end{array}$ & $\begin{array}{l}\text { Formaldehyde } \\
\qquad \begin{array}{c}(\mathrm{mL}) \\
(\mathrm{mol})\end{array}\end{array}$ & $\begin{array}{c}\text { Mole ratio } \\
F:(P+A)\end{array}$ & $\begin{array}{c}\text { Catalyst } \\
{\left[\mathrm{Mg}(\mathrm{OH})_{2}\right]} \\
(\mathrm{g}) \\
(\mathrm{mol})\end{array}$ & Co-catalyst \\
\hline $\begin{array}{l}\text { LSPR- } \\
1\end{array}$ & $\begin{array}{c}7.11 \\
(0.068)\end{array}$ & $\begin{array}{c}1.60 \\
(0.0171)\end{array}$ & $\begin{array}{c}10.4 \\
(0.128)\end{array}$ & 1.5 & $\begin{array}{c}0.08 \\
(0.0013)\end{array}$ & -- \\
\hline $\begin{array}{l}\text { LSPR- } \\
\quad 2\end{array}$ & $\begin{array}{c}7.11 \\
(0.068)\end{array}$ & $\begin{array}{c}1.60 \\
(0.0171)\end{array}$ & $\begin{array}{c}10.4 \\
(0.128)\end{array}$ & 1.5 & $\begin{array}{c}0.08 \\
(0.0013)\end{array}$ & $\begin{array}{c}\text { Ammonia } \\
5 \mathrm{~mL}\end{array}$ \\
\hline $\begin{array}{l}\text { LSPR- } \\
3\end{array}$ & $\begin{array}{c}7.11 \\
(0.068)\end{array}$ & $\begin{array}{c}1.60 \\
(0.0171)\end{array}$ & $\begin{array}{c}10.4 \\
(0.128)\end{array}$ & 1.5 & $\begin{array}{c}0.08 \\
(0.0013)\end{array}$ & $\begin{array}{c}\text { Ammonia } \\
10 \mathrm{~mL}\end{array}$ \\
\hline $\begin{array}{l}\text { LSPR- } \\
\quad 4\end{array}$ & $\begin{array}{c}7.11 \\
(0.068)\end{array}$ & $\begin{array}{c}1.60 \\
(0.0171)\end{array}$ & $\begin{array}{c}10.4 \\
(0.128)\end{array}$ & 1.5 & $\begin{array}{c}0.08 \\
(0.0013)\end{array}$ & $\begin{array}{c}\mathrm{Ca}(\mathrm{OH})_{2} \\
0.160 \mathrm{~g}\end{array}$ \\
\hline $\begin{array}{l}\text { LSPR- } \\
5\end{array}$ & $\begin{array}{c}7.11 \\
(0.068)\end{array}$ & $\begin{array}{c}1.60 \\
(0.0171)\end{array}$ & $\begin{array}{c}10.4 \\
(0.128)\end{array}$ & 1.5 & $\begin{array}{c}0.08 \\
(0.0013)\end{array}$ & $\begin{array}{c}\mathrm{NH}_{4} \mathrm{Cl} \\
0.160 \mathrm{~g}\end{array}$ \\
\hline
\end{tabular}

Table 2. GC results of free phenol and free aniline

\begin{tabular}{ccc} 
Sample code & Phenol $\%(\mathrm{w} / \mathrm{w})$ & Aniline $\%(\mathrm{w} / \mathrm{w})$ \\
LSPR-1 & 10.2 & 0.2 \\
LSPR-2 & 9.4 & 8.1 \\
LSPR-3 & 13.7 & 14.9 \\
LSPR-4 & 8.7 & 7.6 \\
LSPR-5 & 9.0 & 0.2 \\
\hline
\end{tabular}




\section{Results and discussion}

Total 5 PAF resins, labeled as LSPR-1, LSP2, LSPR-3, LSPR-4 and LSPR-5, were synthesized using different catalyst and concentration of ammonia. LSPR-5 was synthesized using magnesium hydroxide and ammonium chloride as reagents to generate in situ ammonia. Our prime aim of study was to generate ammonia in situ and see the effect on properties of resins. Our assumption was that in situ generated ammonia based PAF resin should show higher thermal stability due to availability of ammonia till end of the reaction in the reaction mixture.

\section{Determination of free phenol and free aniline}

Analysis of free phenol and free aniline has lot of importance, because it gives rough idea about whether the added phenol or aniline is fully reacted or not. The analyzed results of free phenol and free aniline of PAF resins are presented in Table 2. Obtained results illustrate that quantity of free aniline and free phenol are different. Particularly LSPR-1 and LSPR-5 displays lower percentage of free aniline. It clearly indicates aniline is almost fully reacted with formaldehyde. LSPR-5 shows phenol percentage is lower compared to other PAF resin samples. Overall conclusion is that our assumption is right, i.e. in situ generation of ammonia helps to reaction move forward, thus it exhibits lower percentages of residual phenol and aniline.

\section{Determination of free formaldehyde}

Titrimetric methods are widely used for the determination of free formaldehyde concentration, because of simplicity and accuracy. Reynolds and Irwin reviewed the different titrimetric methods available for measuring small quantities of formaldehyde and concluded that sodium sulphite method is a simple and adaptable method for the determination of formaldehyde [21]. When formaldehyde reacts with sodium sulphite, it forms formaldehyde bisulphite as an addition product and sodium hydroxide is liberated. The amount of sodium hydroxide produced is determined by titrimetrically.

Into a conical flask, $10 \mathrm{~mL}$ sodium sulphite solution and approximate $0.2 \mathrm{~g}$ of sample were added and the mixture was swirled for five minutes. Then 1-2 drops of $1 \%$ ethanolic thymolphthalein indicator solution was added and titrated with $0.25 \mathrm{~N}$ sulphuric acid solution. Obtained results are presented in Table 3. It indicates that free formaldehyde is in the range.

Table 3. Free formaldehyde content of phenol-aniline-formaldehyde resins

\begin{tabular}{ccc} 
Resin code & Mass of resin $(\mathrm{g})$ & HCHO (mole) \\
LSPR-1 & 0.202 & 0.024 \\
LSPR-2 & 0.208 & 0.020 \\
LSPR-3 & 0.210 & 0.029 \\
LSPR-4 & 0.206 & 0.026 \\
LSPR-5 & 0.210 & 0.025 \\
\hline
\end{tabular}

Table 4. Elemental analysis, inherent viscosity, molecular weight and gel time of phenol-anilineformaldehyde resins

\begin{tabular}{|c|c|c|c|c|c|c|}
\hline \multirow[t]{2}{*}{ Sample code } & \multicolumn{3}{|c|}{ Elements (\%) } & \multirow{2}{*}{$\begin{array}{c}\text { Viscosity } \\
\text { (dL/g) }\end{array}$} & \multirow{2}{*}{$\begin{array}{l}\text { Mol. Wt. } \\
\text { (g/mol) }\end{array}$} & \multirow{2}{*}{$\begin{array}{l}\text { Gel time } \\
\text { (Sec) }\end{array}$} \\
\hline & $\mathrm{C}$ & $\mathrm{H}$ & $\mathrm{N}$ & & & \\
\hline LSPR-1 & 69.72 & 6.34 & 2.27 & 0.059 & 587.0 & 66 \\
\hline LSPR-2 & 72.72 & 6.22 & 9.61 & 0.061 & 554.8 & 58 \\
\hline LSPR-3 & 73.21 & 6.40 & 9.80 & 0.046 & 529.0 & 62 \\
\hline LSPR-4 & 72.85 & 6.51 & 10.66 & 0.052 & 618.3 & 78 \\
\hline LSPR-5 & 74.14 & 6.24 & 4.24 & 0.068 & 581.0 & 63 \\
\hline
\end{tabular}


Elemental analysis, inherent viscosity, molecular weights and gel time

The elemental analysis, inherent viscosity, molecular weight and gel time of resins are presented in Table 4.

Elemental analysis of PAF resins shows supporting results to our assumption as mentioned in determination of free phenol and free aniline paragraph. LSPR-1 and LSPR5 depicts lower percentage of nitrogen compared to other PAF resins. It clearly demonstrates that aniline is fully reacted with formaldehyde. It also shows percentage of carbon is also higher.

Dilute solution viscosity methodology was applied to determine the viscosity of polymers. Viscosity of polymers provides the idea of rough molecular weight of resins or polymers. Particularly cross-linked PAF resins are insoluble in common organic solvents. In our case, all PAF resins are soluble in THF solvent. Viscosity of all polymers is lower. It describes that PAF resins are oligomeric in nature.

Molecular weights of polymer samples were determined using vapour pressure osmometer K-7000 using THF as solvent at 38 ${ }^{\circ} \mathrm{C}$. Benzil was used as standard. Obtained results illustrate that PAF resins are oligomeric in nature.

Gel time is the technique which is used to measure curing time of thermosetting polymers at constant temperature. The gel time of resins was measured at constant temperature $\left(100^{\circ} \mathrm{C}\right)$ in a closed oven. The gel time of LSPR-5 resin is lower compared to other PAF resins except LSPR-2.

\section{Infrared spectroscopy}

Infrared spectroscopy of PAF resins was carried out in $\mathrm{KBr}$ pellet and is depicted in Figure 1. The characteristic peaks of the phenol-aniline-formaldehyde resins are assigned using literature values [22-24]. Peaks appeared at 1001 and $1110 \mathrm{~cm}^{-1}$ corresponds to the C-O-C asymmetric stretching and aliphatic hydroxy group respectively, while $962 \mathrm{~cm}^{-1}$ peak assigned to the 1,2,4-substituted benzene ring. The peak observed at $1228-1258 \mathrm{~cm}^{-1}$ is attributed to the asymmetric stretching of phenolic $\mathrm{C}-\mathrm{C}-\mathrm{OH}$ group. The peak displayed at $1370 \mathrm{~cm}^{-1}$ corresponds to the -HO group in plane. The peaks observed at $1450 \mathrm{~cm}^{-1}$ assigned to $\mathrm{C}-\mathrm{H}$ bending, and peaks observed at 1500 and $1600 \mathrm{~cm}^{-1}$ ascribed to the $\mathrm{C}=\mathrm{C}$ aromatic stretching. The peak at appeared $2830 \mathrm{~cm}^{-1}$ corresponds to the stretching vibration of $\mathrm{CH}_{2^{-}}$out of plane, while the $3045 \mathrm{~cm}^{-1}$ peak belongs to the stretching vibration of $-\mathrm{CH}_{2}$ - in phase.
Figure 1. IR spectrum of phenol-aniline-formaldehyde resins (LSPR-5)

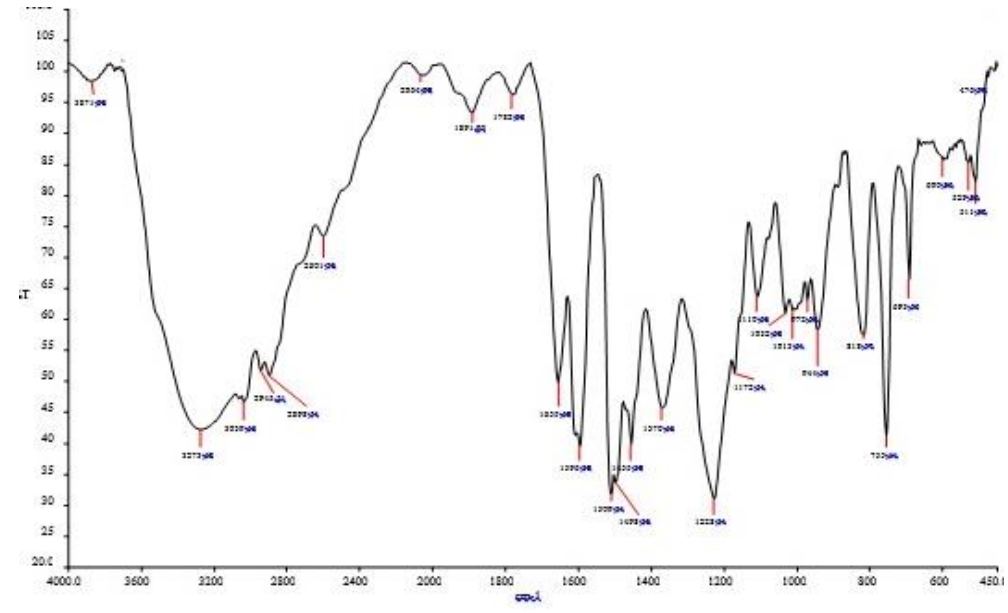


Figure 2. ${ }^{1} \mathrm{H}$ NMR spectrum of phenol-aniline-formaldehyde resin (LSPR-5)
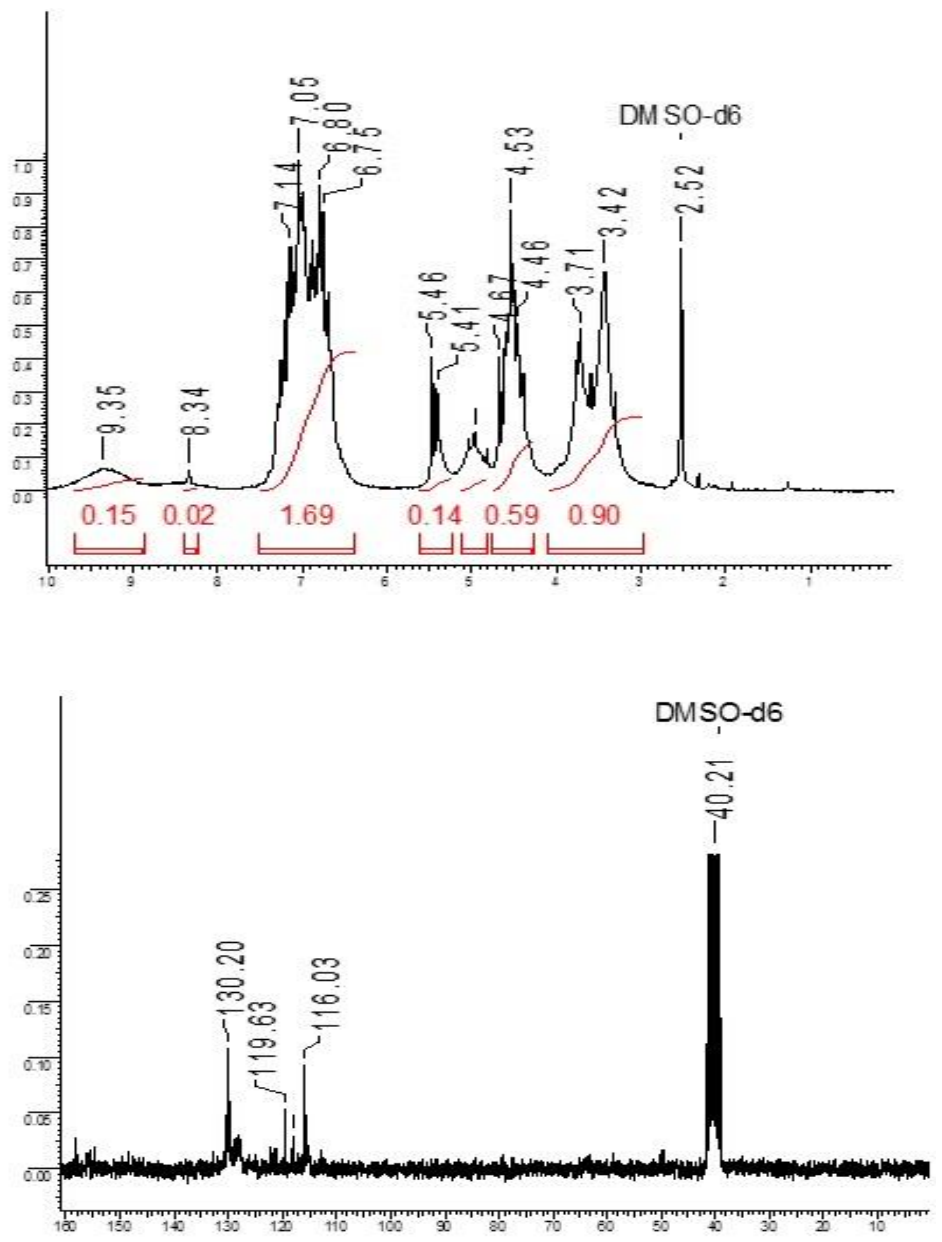

Figure 3. ${ }^{13} \mathrm{C}$ spectrum of phenolaniline-formaldehyde resin (LSPR-5)

\section{${ }^{1}$ H NMR spectroscopy}

The ${ }^{1} \mathrm{H}$ NMR spectrum of phenol-anilineformaldehyde resin (LSPR-1) is presented in Figure 2. The most of chemical peaks in anilinephenol-formaldehyde resins are assigned based on previous literature studies $[25,26]$. ${ }^{1} \mathrm{H}$ NMR spectrum of synthesized uncured phenolaniline-formaldehyde resole resins showed dibenzyl ether and methylene bridges are formed. The chemical shift observed at 3.42$3.71 \delta$ (ppm) corresponds to the methylene proton of $\mathrm{Ar}-\mathrm{CH}_{2}$ bridge. The signal obtained in the region of 4.53-4.67 $\delta$ (ppm) may be attributed to dibenzyl ether bridges $\left(\mathrm{Ar}-\mathrm{CH}_{2}-\mathrm{O}-\right.$ $\mathrm{CH}_{2}-\mathrm{Ar}$ ) and methylol functional groups. The peak at $4.96 \delta$ (ppm) corresponds to the aromatic $-\mathrm{NH}_{2}$. The peak in the region 5.41-5.45 $\delta(\mathrm{ppm})$ may be due to the proton of phenolic OH group. The strong signal in the region 6.76$7.05 \delta$ (ppm) corresponds to the aromatic protons.

\section{${ }^{13}$ C NMR spectroscopy}

The ${ }^{13} \mathrm{C}$ NMR spectrum of phenol-anilineformaldehyde resin (LSPR-1) is presented in Figure 3. The most characteristic chemical shifts are assigned on the basis of data available in the literature [27-30]. In present study, peaks for substituted and unsubstituted phenolic rings carbon were observed in complex region between 116 and $130 \mathrm{ppm}$. The peak observed at $116 \mathrm{ppm}$ corresponds to the unsubstituted ortho aromatic carbon. The ${ }^{13} \mathrm{C}$ NMR of resin also shows peak at $119 \mathrm{ppm}$ attributed to unsubstituted aromatic carbon. Another type of chemical shift was observed at 130 ppm corresponds to substituted para aromatic carbon. The peaks at 57,62 and 80 ppm (depth) attributed to the co-condensed methylene phenolic para aromatic carbon, para methylol 
and reactive formaldehyde adduct respectively. It was also observed that there is a peak at the $50 \mathrm{ppm}$ region indicates that self-condensation phenol-methylol might have occurred.

\section{Differential scanning colorimetry (DSC)}

Differential scanning calorimetry (DSC) analysis of PAF was carried out on DSC Q-10. DSC technique is used to get a thermal profile of the investigated sample under the conditions of thermal dynamic or isothermal scanning. The results of the measurements produce the knowledge of the reaction behavior, the beginning, the end and at which point the reaction reach its maximum peak. It also provides the heat of reaction and the glass transition temperature when operated under dynamic scanning. Glass transition temperature of LSPR-5 is lower compared to other PAF resins as mentioned in Table 5. It also clearly supports to our assumption expressed in free phenol and free aniline paragraph. When aniline inserted into phenol-formaldehyde resin, it increases flexibility, thus reduction in glass transition temepature. This is the special property of aniline [31].

The comparative DSC plots of PAF resins presented in Figure 4. All resins show peak in the temperature range $70-110^{\circ} \mathrm{C}$ related to the chain building condensations reaction involving both hydroxymethyl group attached to various phenolic species and self-condensation of 4hydroxybenzyl alcohol [32-33]. The LSPR-5 PAF resin shows different nature of thermogram compared to the other resins. It displays two endothermic peaks in the temperature range of $140^{\circ} \mathrm{C}-150^{\circ} \mathrm{C}$ indicates formation of crystallization phenomena resulting melting transitions.

Table 5. Glass transition temperature (Tg) of phenol-aniline-formaldehyde resins

$\begin{array}{ccc}\text { Sr. No. } & \text { Sample code } & \mathrm{Tg}\left({ }^{\circ} \mathrm{C}\right) \\ 1 & \text { LSPR-1 } & 108 \\ 2 & \text { LSPR-2 } & 110 \\ 3 & \text { LSPR-3 } & 85.6 \\ 4 & \text { LSPR-4 } & 97.8 \\ 5 & \text { LSPR-5 } & 72\end{array}$

Table 6. $\mathrm{T}_{\max }$ of phenol-aniline-formaldehyde resins

\begin{tabular}{ccccc} 
Sample code & \multicolumn{3}{c}{$\mathrm{T}_{\max }\left({ }^{\circ} \mathrm{C}\right)$} & Residue left \\
& 1 & 2 & 3 & $(\%)$ \\
LSPR-1 & 170 & 254 & 528 & 47 \\
LSPR-2 & 162 & 203 & 527 & 48 \\
LSPR-3 & 159 & 244 & 516 & 49 \\
LSPR-4 & 161 & 210 & 528 & 50 \\
LSPR-5 & 204 & 397 & 546 & 47 \\
\hline
\end{tabular}

Figure 4. DSC comparative thermograms of phenolaniline-formaldehyde resins

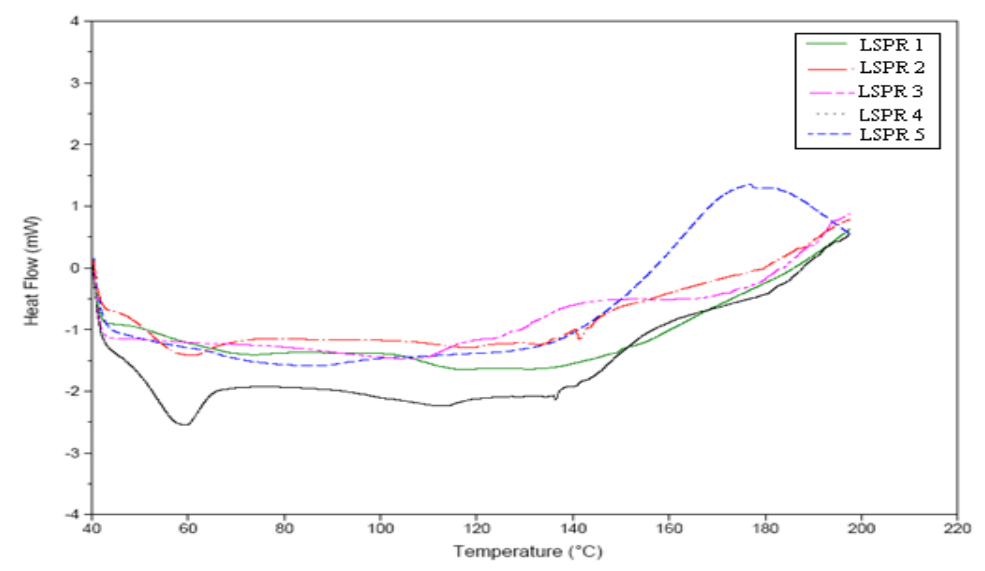


Thermogravimetric analysis

Thermogravimetric analysis (TGA) is an important analysis that shows the thermal stability of the materials. Also, it dictates the profile of decomposition process and char yield of the material associated with the thermal treatment. Maximum decomposition temperature of PAF resins is illustrated in Table 6. LSPR-5 shows highest maximum decomposition temperature $\left(\mathrm{T}_{\max }\right)$, i.e. $397^{\circ} \mathrm{C}$, as compared to other resins. Thus, it suggests that incorporation of aniline improves thermal stability of PAF resin.

Figure 5 represents the TGA thermograms of LSPR-1, LSPR-2, LSPR-3, LSPR-4 and LSPR5 PAF resins. PAF resins show that the weight loss is implemented in two steps. The first weight loss, around $20 \%$, was observed in the temperature range of 160 to $210{ }^{\circ} \mathrm{C}$ which is attributed to water and residual amount of formaldehyde remained in resin. The second weight loss, around $30 \%$, was appeared in the temperature range of 510 to $550{ }^{\circ} \mathrm{C}$ which is due to breakage of methylene linkages of resin yields aldehyde and phenols. Finally around $40 \%$ mass remains as coke-like solid mass residue. The comparative results of $\mathrm{T}_{\max }$ are presented in Table 6.

The TGA thermogram of LSPR- 5 shows anomalous behavior. The first weight loss, around $10 \%$, was observed in the temperature range of 160 to $200{ }^{\circ} \mathrm{C}$ which attributed to loss of water and residual amount of formaldehyde remained in resin. The second weight loss, around $20 \%$, was appeared in the temperature range of 350 to $450{ }^{\circ} \mathrm{C}$ which assigned to degradation of aniline. The third weight loss, around $20 \%$, was appeared in the temperature range of 450 to $550{ }^{\circ} \mathrm{C}$ which is ascribed to degradation of methylene linkages of PAF resins.

\section{MALDI-TOF analysis}

The MALDI-TOF spectra of phenolic resin were recorded on instrument Voyager-DE STR Boisystem. The duration of a single laser pulse was 2 nsec. The conditions for the measurement of spectrum are as follows; mode of operation-linear, polarity-positive, accelaration voltage $20000 \mathrm{~V}$ and 100 pulses per spectrum. The delayed extraction technique was used applying delay times 100 nsec. The matrix, sinapinic acid solution and CTAB solution were used. The sample solutions were prepared in THF by dissolving phenolic resin having concentration $10 \mu \mathrm{m} / \mathrm{L}$ of each sample solution. The solution of matrix and sample were mixed in equal amounts and $0.5-1.0 \mu \mathrm{L}$ of resulting solution were deposited on MALDI plate. The MALDI plate was introduced into the spectrometer after evaporation of solvent. The spectrum obtained from MALDI analysis is shown in Figure 6. Table 7 represents assignment of MALDI-TOF fragmentation peaks of PAF resins.

Table 7. MALDI-TOF fragmentation peaks of the phenol-aniline-formaldehyde resin

\begin{tabular}{|c|c|c|}
\hline $\begin{array}{c}\text { Experimental } \\
\mathrm{M}+\mathrm{Na}^{+}+\mathrm{K}^{+}\end{array}$ & $\begin{array}{l}\text { Theoretical } \\
\mathrm{M}+\mathrm{Na}^{+}+\mathrm{K}^{+}\end{array}$ & Oligomer type \\
\hline 463 & 458 & $\mathrm{P}-\mathrm{CH}_{2}-\mathrm{A}-\mathrm{CH}_{2}-\mathrm{P}-\mathrm{CH}_{2}-\mathrm{A}$ \\
\hline 515 & 518 & $\mathrm{HOCH}_{2}-\mathrm{P}-\mathrm{CH}_{2}-\mathrm{A}-\mathrm{CH}_{2}-\mathrm{P}-\mathrm{CH}_{2}-\mathrm{A}-\mathrm{CH}_{2} \mathrm{OH}$ \\
\hline 548 & 552 & $\mathrm{HOCH}_{2}-\mathrm{P}-\mathrm{CH}_{2}-\mathrm{A}-\mathrm{CH}_{2}-\mathrm{P}\left(\mathrm{CH}_{2} \mathrm{OH}\right)-\mathrm{CH}_{2}-\mathrm{A}-\mathrm{CH}_{2} \mathrm{OH}$ \\
\hline 685 & 685 & $\mathrm{HOCH}_{2}-\mathrm{P}-\mathrm{CH}_{2}-\mathrm{A}-\mathrm{CH}_{2}-\mathrm{P}\left(\mathrm{CH}_{2} \mathrm{OH}\right)-\mathrm{CH}_{2}-\mathrm{A}-\mathrm{CH}_{2}-\mathrm{P}-\mathrm{CH}_{2} \mathrm{OH}$ \\
\hline 741 & 745 & $\begin{array}{c}\mathrm{HOCH}_{2}-\mathrm{P}-\mathrm{CH}_{2}-\mathrm{A}\left(\mathrm{CH}_{2} \mathrm{OH}\right)-\mathrm{CH}_{2}-\mathrm{P}\left(\mathrm{CH}_{2} \mathrm{OH}\right)-\mathrm{CH}_{2}-\mathrm{A}\left(\mathrm{CH}_{2} \mathrm{OH}\right)- \\
\mathrm{CH}_{2}-\mathrm{P}-\mathrm{CH}_{2} \mathrm{OH}\end{array}$ \\
\hline 959 & 966 & $\begin{array}{c}\mathrm{HOCH}_{2}-\mathrm{P}-\mathrm{CH}_{2}-\mathrm{A}\left(\mathrm{CH}_{2} \mathrm{OH}\right)-\mathrm{CH}_{2}-\mathrm{P}\left(\mathrm{CH}_{2} \mathrm{OH}\right)-\mathrm{CH}_{2}-\mathrm{A}\left(\mathrm{CH}_{2} \mathrm{OH}\right)- \\
\mathrm{CH}_{2}-\mathrm{P}-\mathrm{CH}_{2}-\mathrm{A}\left(\mathrm{CH}_{2} \mathrm{OH}\right)-\mathrm{CH}_{2}-\mathrm{P}-\mathrm{CH}_{2} \mathrm{OH}\end{array}$ \\
\hline
\end{tabular}


Figure 5. TGA plots of phenolaniline-formaldehyde resins

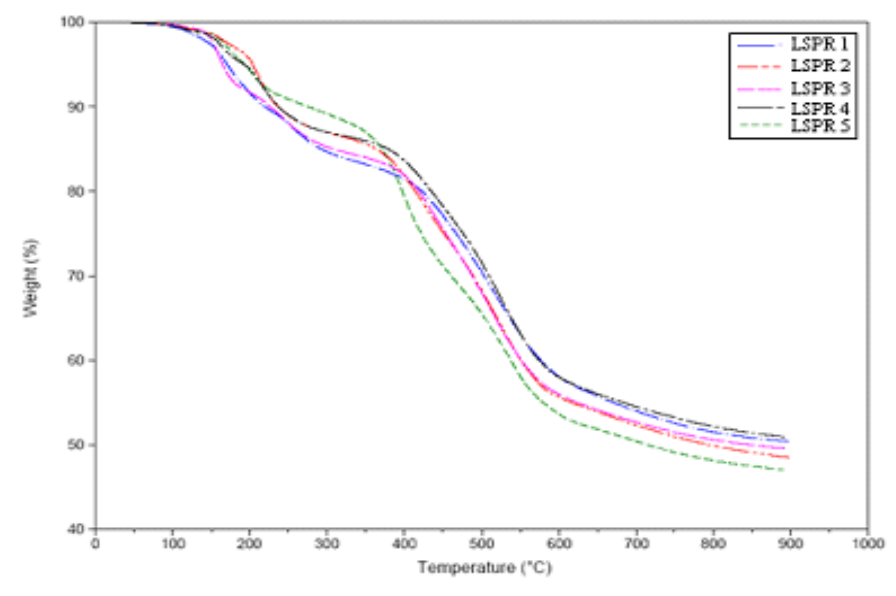

Figure 6. MALDI-TOF analysis of phenol-anilineformaldehyde resin (LSPR-5)

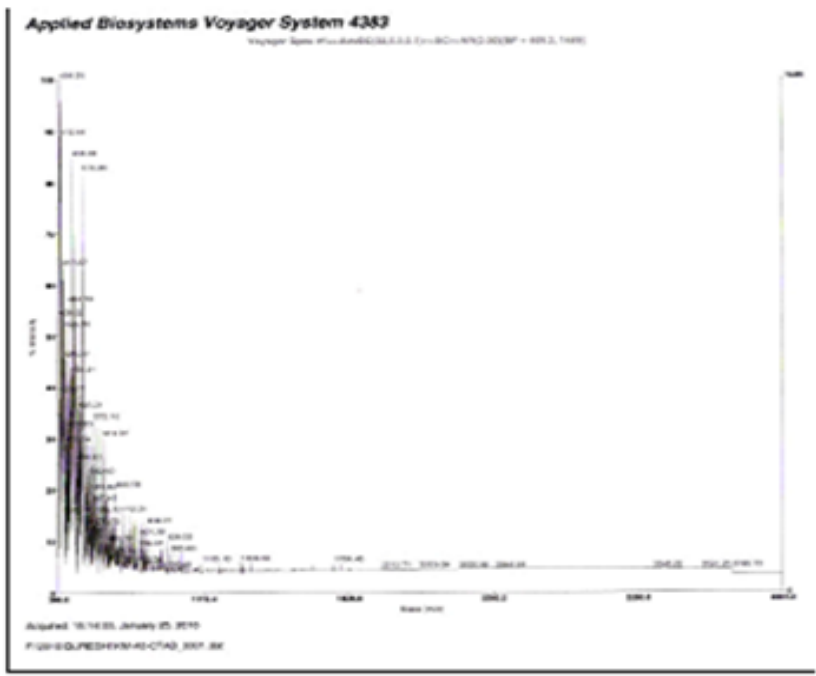

Table 7 summarizes the fragmentation peaks of phenolic resins. In this study, $\mathrm{NaCl}$ and $\mathrm{KCl}$ were used as ionizing agents; the peaks represented Phenolic resin $+\mathrm{Na}^{+}+\mathrm{K}^{+}$ e.g. peak observed at $463 \mathrm{~m} / \mathrm{z}$ which was calculated as $401 \mathrm{~m} / \mathrm{z}$; molar mas of phenolic resin $+23 \mathrm{~m} / \mathrm{z}\left(\mathrm{MW}\right.$ of $\mathrm{Na}^{+}$) and $39 \mathrm{~m} / \mathrm{z}$ (MW of $\mathrm{K}^{+}$). As shown in the Table 7, the six major fragmentations peaks and were observed in MALDI-TOF spectrum and presents their possible oligomer type. This data shows that maximum molecular weight $(1000 \mathrm{~m} / \mathrm{z})$ of aniline-formaldehyde resins was achieved.

\section{Conclusion}

The cross-linking of phenol-anilineformaldehyde resins depends on the type of basic catalyst and amount of formaldehyde. In this work, novel method was developed for the synthesis of ammonia i.e. in situ. Synthesized PAF resins with and without in suit generation of ammonia were studied. Our assumption was that in situ generated ammonia based PAF resin should show higher thermal stability due to availability of ammonia till end of the reaction in the reaction mixture and it is proved on the basis of DSC, TGA, free phenol and free aniline and gel time determination. LSPR-5, based on in situ generation of ammonia, displays lower percentage of free aniline compared to other PAF resins. It clearly indicates aniline is almost fully reacted with formaldehyde. LSPR-5 also shows lower percentage of phenol compared to other PAF resins. It also 
clearly supports to our assumption. Overall conclusion is that our assumption is right, i.e. in situ generation of ammonia helps to reaction move forward, thus it exhibits lower percentages of residual phenol and aniline.

\section{Acknowledgement}

This study was financially supported by Department of Science and Technology (DST), Government of India, New Delhi, under grant number SR/S3/CE/0049/2010.

\section{Disclosure statement}

No potential conflict of interest was reported by the authors.

\section{References}

[1] (a) A. Pizzi, Advanced Wood Adhesives Technology, Marcel Dekker, New York, Basel, 1994; (b) G. Brode, In KirkOthmer Encyclopedia of Chemical Technology, $3^{\text {rd }}$ ed., Vol. 17, Wiley, New York, 1981, pp. 384-416.

[2] A. Knop, L. Pilato, Phenolic ResinsChemistry, Applications and Performance, Spinger-Verlag, Berlin, Germany, 1985, 68.

[3] (a) G. Astarloa-Aierbe, J. Echeverria, A. ázquez, I. Mondragon, Polymer, 2000, 41, 3311-3315; (b) G.N. Manikandan, K. Bogeshwaran, Int. J. ChemTech Res., 2016, 9, 30-37; (c) W.J. Lee, C.L. Kang, K.C. Chang, Y.C. Chen, Holzforschung, 2012, 66, 67-72.

[4] (a) G. Astarloa-Aierbe, J. Echeverria, M. Martin, A. Exteberria, I. Mondragon, Polymer, 2000, 41, 6797-6802; (b) L. Uyigue, E. Kubiangha, IOSR J. Engg. (IOSRJEN), 2018, 8, 14.

[5] P. Kopf, Phenolic Resins: Encyclopedia of Polymer Science and Technology, 2002, 7, 322.

[6] L. Pilato, Phenolic Resins: A Century of Progress, Springer, Verlag Berlin Heidelberg, 2010, ISBN 978-3-642-
04713-8

[7] S. So, A. Rudin, J. Appl. Polym. Sci., 1990, 41, 205-232.

[8] (a) M.F. Grenier-Loustalot, S. Larroque, P. Grenier, Polymer 1996, 37, 639-650; (b) K. Srivastava, C. Kumar, D. Srivastava, S. Tripathi. Macromolecul. Ind. J., 2007, 3, 176.

[9] T. Holopainen, L. Alvila, J. Rainio, T.T. Pakkanen, J. Appl. Polym. Sci., 1997, 66, 1183-1193.

[10] B. Me'chin, D. Hanton, J. Le Goff, J. Tanneur, Eur. Polym. J., 1986, 22, 115124.

[11] N. Meyer, M. Cousin, 1985, US Patent 4, $555,544 \mathrm{~A}$.

[12] (a) H. Bender, N. Bloomfield, 1934, US Patent 1,955,731; (b) Peep Christjanson, Tõnis Pehk, and Jane Paju, Proc. Estonian Acad. Sci., 2010, 59, 225-232.

[13] V. Studentsov, S. Artemenko, Vysokomol. Soyed., 1976, A18, 443.

[14] A. Ingrassia, Laurel, Miss., 1954, US Patent 2,666,037.

[15]. H. Daibor and J. Kiihr, 1966, US Patent $3,256,222$

[16] (a) K. Jellinek, R. Miller; G. Wisomirski, 1987, US Patent 4,663,418; (b) Y. Chen, D. Fan, T. Quin, F. Chu, BioResourses, 2014, 9, 4063-4075; (c) J. Wang, Y. Zhang, Polymer-Plastics Tech. Engg., 2012, 51, 1213-1217.

[17] N. Isamu, J. Appl. Polym. Sci., 1976, 20, 799-807.

[18] F. Dong-Bin, L. Gai-Yun, Q. Te-Fu, C. FuXiang, Polymers, 2014, 6, 2221-2231.

[19] D. Fraser, R. Hall, A. Raum, J. Appl. Chem., 1957, 7, 676.

[20] J. Huang, M. Xu, Q. Ge, M. Lin, Q. Lin, Y. Chen, J. Chu, L. Dai, Y. Zou, J. Appl. Polym. Sci., 2005, 97, 652-658.

[21] J. Reynolds, M. Irwin, Chem. and Ind., 1948, 419.

[22] V. Erä, H. Salo, T. Kaps, J. Lindberg, Angew Makromol. Chem., 1975, 48, 185.

[23] R. Ebewele, B. River, J. Koutsky, J. Appl. 
Polym. Sci., 1986, 31, 2275-2302.

[24] G. Carotenuto, L. Nicolais, J. Appl. Polym. Sci., 1999, 74, 2703-2715.

[25] R. Samal, B. Senapati, T. Behuray, J. Appl. Polym. Sci, 1996, 62, 655-660.

[26] B. Furniss, A. Hannaford, P. Smith, and A. Tatchell, Vogel's Text Book of Practical Organic Chemistry; Addison Wesley Longman Ltd. England, First ISE Reprint, 1998.

[27] A. Pizzi, H. Pasch, C. Simon, K. Rode, J. Appl. Polym. Sci., 2004, 92, 2665-2674.

[28] T. Fisher, P. Chao, C.G. Upton, A.J. Day, Magn. Reson. Chem., 1995, 33, 717-723.
[29] B.T. Ottenbourgs, P.J. Adriaensens, B.J. Reekmans, R.A. Carleer, D.J. Vanderzande, J.M. Gelan, Ind. Eng. Chem. Res., 1995, 34, 1364-1370.

[30] H. Pasch, P. Goetzky, E. Grundemann, H. Raubach, Acta. Polym. 1981, 32, 14-18.

[31] T. Amra, Ph D Thesis: Flexibilizition of phenolic resin, The Technical University of Denmark, Department of Chemical Engineering, Lyngby, 2004.

[32] A.W. Christiansen, L. Gollob, J. Appl. Polym. Sci., 1985, 30, 2279-2289.

[33] M.A. Khan, S.M. Ashraf, V.P. Malhotra, J. Appl. Polym. Sci., 2004, 92, 3514-3523.

How to cite this manuscript: Apparav Wale, Khudbudin Mulani, Kamini Donde, Surendra Ponrathnam, Nayaku Chavan, In Situ Generation of Ammonia: An Efficient Catalyst for The Synthesis Of Phenol-Aniline-Formaldehyde Resol Resins, Adv. J. Chem. A, 2020, 3(2), 146158. 